\title{
The relations between Lamarckism and Darwinism; Neolamarckism ${ }^{\dagger}$
}

\author{
Alpheus Spring Packard
}

Since the appearance of Darwin's Origin of Species, and after the great naturalist had converted the world to a belief in the general doctrine of evolution, there has arisen in the minds of many working naturalists a conviction that natural selection, or Darwinism as such, is only one of other evolutionary factors; while there are some who entirely reject the selective principle. Darwin, moreover, assumed a tendency to fortuitous variation, and did not attempt to explain its cause. Fully persuaded that he had discovered the most efficient and practically sole cause of the origin of species, he carried the doctrine to its extreme limits, and after over twenty years of observation and experiment along this single line, pushing entirely aside the Erasmus Darwin and Lamarckian factors of change of environment, though occasionally acknowledging the value of use and disuse, he triumphantly broke over all opposition, and lived to see his doctrine generally accepted. He had besides the support of some of the strongest men in science: Wallace in a twin paper advocated the same views; Spencer, Lyell, Huxley, Hooker, Haeckel, Bates, Semper, Wyman, Gray, Leidy, and other representative men more or less endorsed Darwin's views, or at least some form of evolution, and owing largely to their efforts in scientific circles and in the popular press, the doctrine of descent rapidly permeated every avenue of thought and became generally accepted.

Meanwhile, the general doctrine of evolution thus proved, and the "survival of the fittest" an accomplished fact, the next step was to ascertain "how", as Cope asked, "the fittest originated?" It was felt by some that natural selection alone was not adequate to explain the first steps in the origin of genera, families, orders, classes, and branches or phyla. It was perceived by some that natural selection by itself was not a vera causa, an efficient agent, but was passive, and rather expressed the results of the operations of a series of factors. The transforming should naturally precede the action of the selective agencies.
We were, then, in our quest for the factors of organic evolution, obliged to fall back on the action of the physico-chemical forces such as light, or its absence, heat, cold, change of climate; and the physiological agencies of food, or in other words on changes in the physical environment, as well as in the biological environment. Lamarck was the first one who, owing to his many years' training in systematic botany and zoölogy, and his philosophic breadth, had stated more fully and authoritatively than any one else the results of changes in the action of the primary factors of evolution. Hence a return on the part of many in Europe, and especially in America, to Lamarckism or its modern form, Neolamarckism. Lamarck had already, so far as he could without a knowledge of modern morphology, embryology, cytology, and histology, suggested those fundamental principles of transformism on which rests the selective principle.

Had his works been more accessible, or, where available, more carefully read, and his views more fairly represented; had he been favored in his lifetime by a single supporter, rather than been unjustly criticised by Cuvier, science would have made more rapid progress, for it is an axiomatic truth that the general acceptance of a working evolutionary theory has given a vast impetus to biology.

We will now give a brief historical summary of the history of opinion held by Lamarckians regarding the causes of the "origin of the fittest" the rise of variations, and the appearance of a population of plant and animal forms sufficiently extensive and differentiated to allow for the play of the competitive forces, and of the more passive selective agencies which began to operate in pre-cambrian times, or as soon as the earth became fitted for the existence of living beings.

The first writer after Lamarck to work along the lines he laid down was Mr. Herbert Spencer. In 1866-71, in his epochal and remarkably suggestive Principles of Biology, the doctrine of use and disuse

${ }^{\dagger}$ The beginning of chapter XX (p. 382-396) from Lamarck the Founder of Evolution, his Life and Work, with Translations of his Writings on Organic Evolution, New York, London and Bombay, 1901. 
is implicated in his statements as to the effects of motion on structure in general ${ }^{1}$; and in his theory as to the origin of the notochord, and of the segmentation of the vertebral column and the segmental arrangement of the muscles by muscular strains ${ }^{2}$, he laid the foundations for future work along this line. $\mathrm{He}$ also drew attention in the same work to the complementary development of parts, and likewise instanced the decreased size of the jaws in the civilized races of mankind, as a change not accounted for by the natural selection of favorable variations ${ }^{3}$. In fact, this work is largely based on the Lamarckian principles, as affording the basis for the action of natural selection, and thirty years later we find him affirming: "The direct action of the medium was the primordial factor of organic evolution" ${ }^{4}$. In his wellknown essay on "The Inadequacy of Natural Selection" (1893) the great philosopher, with his accustomed vigor and force, criticises the arguments of those who rely too exclusively on Darwinism alone, and especially Neodarwinism, as a sufficient factor to account for the origin of special structures as well as species.

The first German author to appreciate the value of the Lamarckian factors was that fertile and comprehensive philosopher and investigator Ernst Haeckel, who also harmonized Lamarckism and Darwinism in these words:

"We should, on account of the grand proofs just enumerated, have to adopt Lamarck's Theory of Descent for the explanation of biological phenomena, even if we did not possess Darwin's Theory of Selection. The one is so completely and directly proved by the other, and established by mechanical causes, that there remains nothing to be desired. The laws of Inheritance and Adaptation are universally acknowledged physiological facts, the former traceable to propagation, the latter to the nutrition of organisms. On the other hand, the struggle for existence is a biological fact, which with mathematical necessity follows from the general disproportion between the average number of organic individuals and the numerical excess of their germs" 5 .
A number of American naturalists at about the same date, as the result of studies in different directions, unbiassed by a too firm belief in the efficacy of natural selection, and relying on the inductive method alone, worked away at the evidence in favor of the primary factors of evolution along Lamarckian lines, though quite independently, for at first neither Hyatt nor Cope had read Lamarck's writings.

In 1866 Professor A. Hyatt published the first of a series of classic memoirs on the genetic relations of the fossil cephalopods. His labors, so rich in results, have now been carried on for forty years, and are supplemented by careful, prolonged work on the sponges, on the tertiary shells of Steinheim, and on the land shells of the Hawaiian Islands.

His first paper was on the parallelism between the different stages of life in the individual and those of the ammonites, carrying out D'Orbigny's discovery of embryonic, youthful, adult, and old-age stages in ammonites ${ }^{6}$, and showing that these forms are due to an acceleration of growth in the mature forms, and a retardation in the senile forms.

In a memoir on the "Biological Relations of the Jurassic Ammonites" progressive changes in these forms, the origination of new genera, and the production of young, mature, and senile forms to "the favorable nature of the physical surroundings, primarily producing characteristic changes which become perpetuated and increased by inheritance within the group".

The study of the modifications of the tertiary forms of Planorbis at Steinheim, begun by Hilgendorf, led among others (nine in all) to the following conclusions:

"First, that the unsymmetrical spiral forms of the shells of these and of all the Mollusca probably resulted from the action of the laws of heredity, modified by gravitation.

"Second, that there are many characteristics in these shells and in other groups, which are due solely to the uniform action of the physical influence of the immediate surroundings, varying with every change of locality, but constant and uniform within each

\footnotetext{
${ }^{1}$ Vol. II, p. 167, 1871.

${ }^{2}$ Vol. II, p. 195.

${ }^{3}$ Vol. I, $\$ 166$, p. 456.

${ }^{4}$ The Factors of Organic Evolution, 1895, p. 460.

${ }^{5}$ Schöpfungsgeschichte, 1868. The History of Creation, New York, II, p. 355.

${ }^{6}$ Alcide d'Orbigny, Paléontologie française, Paris, 1840-59.

${ }^{7}$ Abstract in Proceedings of the Boston Society of Natural History, XVII, December 16, 1874.
} 
locality.

"Third, that the Darwinian law of Natural Selection does not explain these relations, but applies only to the first stages in the establishment of the differences between forms or species in the same locality. That its office is to fix these in the organization and bring them within the reach of the laws of heredity".

These views we find reiterated in his later palæontological papers. Hyatt's views on acceleration were adopted by Neumayr ${ }^{8}$. Waagen ${ }^{9}$, from his studies on the Jurassic cephalopods, concludes that the factors in the evolution of these forms were changes in external conditions, geographical isolation, competition, and that the fundamental law was not that of Darwin, but "the law of development". Hyatt has also shown that at first evolution was rapid. "The evolution is a purely mechanical problem in which the action of the habitat is the working agent of all the major changes; first acting upon the adult stages, as a rule, and then through heredity upon the earlier stages in successive generations". He also shows that as the primitive forms migrated and occupied new, before barren, areas, where they met with new conditions, the organisms "changed their habits and structures rapidly to accord with these new conditions" ${ }^{10}$.

While the palæontological facts afford complete and abundant proofs of the modifying action of changes in the environment, Hyatt, in 1877, from his studies on sponges ${ }^{11}$, shows that the origin of their endless forms "can only be explained by the action of physical surroundings directly working upon the organization and producing by such direct action the modifications or common variations above described".

Mr. A. Agassiz remarks that the effect of the nature of the bottom of the sea on sponges and rhizopods "is an all-important factor in modifying the organism"12.
While Hyatt's studies were chiefly on the ammonites, molluscs, and existing sponges, Cope was meanwhile at work on the batrachians. His Origin of Genera appeared shortly after Hyatt's first paper, but in the same year (1866). This was followed by a series of remarkably suggestive essays based on his extensive palæontological work, which are in part reprinted in his Origin of the Fittest (1887); while in his epoch-making book, The Primary Factors of Organic Evolution (1896), we have in a condensed shape a clear exposition of some of the Lamarckian factors in their modern Neolamarckian form.

In the Introduction, p. 9, he remarks:

"In these papers by Professor Hyatt and myself is found the first attempt to show by concrete examples of natural taxonomy that the variations that result in evolution are not multifarious or promiscuous, but definite and direct, contrary to the method which seeks no origin for variations other than natural selection. In other words, these publications constitute the first essays in systematic evolution that appeared. By the discovery of the paleontologic succession of modifications of the articulations of the vertebrate, and especially mammalian, skeleton, I first furnished an actual demonstration of the reality of the Lamarckian factor of use, or motion, as friction, impact, and strain, as an efficient cause of evolution ${ }^{13}$ ".

The discussion in Cope's work of kinetogenesis, or of the effects of use and disuse, affords an extensive series of facts in support of these factors of Lamarck's. As these two books are accessible to every one, we need only refer the reader to them as storehouses of facts bearing on Neolamarckism.

The present writer, from a study of the development and anatomy of Limulus and of Arthropod ancestry, was early $(1870)^{14}$ led to adopt Lamarckian views in preference to the theory of Natural Selection, which never seemed to him adequate or sufficiently comprehensive to explain the origin of

\footnotetext{
${ }^{8}$ Zeitschr. der deutsch. geol. Gesellschaft, 1875.

${ }^{9}$ Paleontologica Indica. Jurassic Fauna of Kutch. I. Cephalopoda, p. 242-243. (See Hyatt's Genesis of the Arietide, p. 27, 42.).

10 "Genera of Fossil Cephalopods", Proc. Bost. Soc. Nat. Hist., XXII, April 4, 1883, p. 265.

11 "Revision of the North American Poriferæ". Memoirs Bost. Soc. Nat. Hist., II, Part IV, 1877.

${ }^{12}$ Three Cruises of the "Blake", 1888, II, p. 158.

${ }^{13}$ The earliest paper in which he adopted the Lamarckian doctrines of use and effort was his "Methods of Creation of Organic Types" (1871). In this paper Cope remarks that he "has never read Lamarck in French, nor seen a statement of his theory in English, except the very slight notices in the Origin of Species and Chambers' Encyclopadia, the latter subsequent to the first reading of this paper". It is interesting to see how thoroughly Lamarckian Cope was in his views on the descent theory.

${ }^{14}$ Proceedings of the American Association for the Advancement of Science, Troy meeting, 1870. Printed in August, 1871.

${ }^{15}$ American Naturalist, V, December, 1871, p. 750. See also p. 751, 759-760.
} 
variations.

In the followingyear ${ }^{15}$, from a study of the insects and other animals of Mammoth Cave, we claimed that "the characters separating the genera and species of animals are those inherited from adults, modified by their physical surroundings and adaptations to changing conditions of life, inducing certain alterations in parts which have been transmitted with more or less rapidity, and become finally fixed and habitual".

In an essay entitled "The Ancestry of Insects"16 (1873) we adopted the Lamarckian factors of change of habits and environment, of use and disuse, to account for the origin of the appendages, while we attributed the origin of the metamorphoses of insects to change of habits or of the temperature of the seasons and of climates, particularly the change in the earth's climates from the earlier ages of the globe, "when the temperature of the earth was nearly the same the world over, to the times of the present distribution of heat and cold in zones".

From further studies on cave animals, published in $1877^{17}$, we wrote as follows:

"In the production of these cave species, the exceptional phenomena of darkness, want of sufficient food, and unvarying temperature, have been plainly enough vere cause. To say that the principle of natural selection accounts for the change of structure is no explanation of the phenomena; the phrase has to the mind of the writer no meaning in connection with the production of these cave forms, and has as little meaning in accounting for the origination of species and genera in general. Darwin' phrase "natural selection", or Herbert Spencer's term "survival of the fittest" expresses simply the final result, while the process of the origination of the new forms which have survived, or been selected by nature, is to be explained by the action of the physical environments of the animals coupled with inheritance-force. It has always appeared to the writer that the phrases quoted above have been misused to state the cause, when they simply express the result of the action of a chain of causes which we may, with Herbert Spencer, call the 'environment' of the organism undergoing modification; and thus a form of Lamarckianism, greatly modified by recent scientific discoveries, seems to meet most of the difficulties which arise in accounting for the origination of species and higher groups of organisms. Certainly 'natural selection' or the 'survival of the fittest' is not a vera causa, though the 'struggle for existence' may show us the causes which have led to the preservation of species, while changes in the environment of the organism may satisfactorily account for the original tendency to variation assumed by $\mathrm{Mr}$. Darwin as the starting point where natural selection begins to act".

In our work on The Cave Animals of North America ${ }^{18}$, after stating that Darwin in his Origin of Species attributed the loss of eyes "wholly to disuse" remarking (p. 142) that after the more or less perfect obliteration of the eyes, "natural selection will often have effected other changes, such as an increase in the length of the antennæ or palpi, as a compensation for blindness", we then summed up as follows the causes of the production of cave fauna in general:

"1. Change in environment from light, even partial, to twilight or total darkness, and involving diminution of food, and compensation for the loss of certain organs by the hypertrophy of others.

"2. Disuse of certain organs.

“3. Adaptation, enabling the more plastic forms to survive and perpetuate their stock.

“4. Isolation, preventing intercrossing with outof-door forms, thus insuring the permanency of the new varieties, species, or genera.

" 5 . Heredity, operating to secure for the future the permanence of the newly originated forms as long as the physical conditions remain the same.

"Natural selection perhaps expresses the total result of the working of these five factors rather than being an efficient cause in itself, or at least constitutes the last term in a series of causes. Hence Lamarckism in a modern form, or as we have termed it, Neolamarckism, seems to us to be nearer the truth than

\footnotetext{
${ }^{16}$ Printed in advance, being Chapter XIII of Our Common Insects, Salem, 1873, p. 172, 174, 179, 180, 181, 185.

17 “A New Cave Fauna in Utah”. Bulletin of the United States Geological Survey, III, April 9, 1877, p. 167.

${ }^{18}$ Memoirs of the National Academy of Sciences, IV, 1888, p. 156; 27 plates. See also American Naturalist, Sept., 1888, XXII, p. 808 , and Sept., 1894, XXVIII, p. 333.

${ }^{19} \mathrm{Carl}$ H. Eigenman, in his elaborate memoir, The Eyes of the Blind Vertebrates of North America (Archiv für Entwickelungsmechanik der Organismen, 1899, VIII), concludes that the Lamarckian view, that through disuse and the transmission by heredity of the characters thus inherited the eyes of blind fishes are diminished, "is the only view so far examined that does not on the face of it present serious objections" (p. 605-609).
} 
Darwinism proper or natural selection ${ }^{19}$ ".

In an attempt to apply Lamarck's principle of the origin of the spines and horns of caterpillars and other insects as well as other animals to the result of external stimuli ${ }^{20}$, we had not then read what he says on the subject. (See p. 316.) Having, however, been led to examine into the matter, from the views held by recent observers, especially Henslow, and it appearing that Lamarck was substantially correct in supposing that the blood (his "fluids") would flow to parts on the exposed portions of the body and thus cause the origin of horns, on the principle of the saying, "ubi irritatio, ibi affluxus", we came to the following conclusions:

"The Lamarckian factors (1) change (both direct and indirect) in the milieu, (2) need, and (3) habit, and the now generally adopted principle that a change of function induces change in organs ${ }^{21}$, and in some or many cases actually induces the hypertrophy and specialization of what otherwise would be indifferent parts or organs; - these factors are allimportant in the evolution of the colors, ornaments, and outgrowths from the cuticle of caterpillars".

Our present views as to the relations between the Lamarckian factors and the Darwinian one of natural selection are shown by the following summary at the end of this essay.

" 1 . The more prominent tubercles, and spines or bristles arising from them, are hypertrophied piliferous warts, the warts, with the seta or hair which they bear, being common to all caterpillars.

" 2 . The hypertrophy or enlargement was probably [we should rather say possibly] primarily due to a change of station from herbs to trees, involving better air, a more equable temperature, perhaps a different and better food.

"3. The enlarged and specialized tubercles developed more rapidly on certain segments than on others, especially the more prominent segments, because the nutritive fluids would tend more freely to supply parts most exposed to external stimuli.

" 4 . The stimuli were in great part due to the visits of insects and birds, resulting in a mimicry of the spines and projections on the trees; the colors (lines and spots) were due to light or shade, with the general result of protective mimicry, or adaptation to treelife.

"5. As the result of some unknown factor some of the hypodermic cells at the base of the spines became in certain forms specialized so as to secrete a poisonous fluid.

"6. After such primitive forms, members of different families, had become established on trees, a process of arboreal segregation or isolation would set in, and intercrossing with low-feeders would cease.

"7. Heredity, or the unknown factors of which heredity is the result, would go on uninterruptedly, the result being a succession of generations perfectly adapted to arboreal life.

"8. Finally the conservative agency of natural selection operates constantly, tending towards the preservation of the new varieties, species, and genera, and would not cease to act, in a given direction, so long as the environment remained the same.

"9. Thus in order to account for the origin of a species, genus, family, order, or even a class, the first steps, causing the origination of variations, were in the beginning due to the primary (direct and indirect) factors of evolution (Neolamarckism), and the final stages were due to the secondary factors, segregation and natural selection (Darwinism)".

From a late essay ${ }^{22}$ we take the following extracts explaining our views:

"In seeking to explain the causes of a metamorphosis in animals, one is compelled to go back to the primary factors of organic evolution, such as the change of environment, whether the factors be cosmical (gravity), physical changes in temperature, effects of increased or diminished light and shade, under- or over-nutrition, and the changes resulting from the presence or absence of enemies, or from isolation. The action of these factors, whether direct or indirect, is obvious, when we try to explain the origin or causes of the more marked metamorphoses

\footnotetext{
20 "Hints on the Evolution of the Bristles, Spines, and Tubercles of Certain Caterpillars, etc." Proceedings Boston Society of Natural History, XXIV, 1890, p. 493-560; 2 plates.

${ }^{21}$ E.J. Marey: "Le Transformisme et la Physiologie Expérimentale, Cours du Collège de France”, Revue Scientifique, $2^{\mathrm{me}}$ serie, IV, p. 818. (Function makes the organ, especially in the osseous and muscular systems.) See also A. Dohrn: Der Ursprung der Wiebelthiere und das Princip des Functionswechsels, Leipzig, 1875. See also Lamarck's opinion, p. 295.

22 "On the Inheritance of Acquired Characters in Animals with a Complete Metamorphosis". Proceedings Amer. Acad. Arts and Sciences, Boston, XXIX (N.S., XXI), 1894, p. 331-370; also monograph of “Bombycine Moths”, Memoirs Nat. Acad. Sciences, VII, 1895 , p. 33.
} 
of animals. Then come in the other Lamarckian factors of use and disuse, new needs resulting in new modes of life, habits, or functions, which bring about the origination, development, and perfection of new organs, as in new species and genera, etc., or which in metamorphic forms may result in a greater increase in the number of, and an exaggeration of the features characterizing the stages of larval life. 